Revista Destaques Acadêmicos, Lajeado, v. 12, n. 3, 2020. ISSN 2176-3070

DOI: http://dx.doi.org/10.22410/issn.2176-3070.v12i3a2020.2692

http://www.univates.br/revistas

\title{
TECNOLOGIAS NÃO INVASIVAS DE CUIDADO NO PARTO: UMA REVISÃO INTEGRATIVA
}

\author{
Noeli Jantsch ${ }^{1}$, Raquel Vieira Schuster ${ }^{2}$
}

\begin{abstract}
Resumo: O presente estudo objetivou identificar o uso das tecnologias obstétricas não invasivas para a promoção do parto humanizado. Realizou-se pesquisa nas bases de dados MEDLINE, BENDENF e LILACS, que incluam textos completos, em português e publicado entre 2015 e 2019 e abordem o uso do banho relaxante, deambulação, cavalinho, bola suíça, essências, musicoterapia, cromoterapia, acupressão e massagem. O banho relaxante está entre as preferências das gestantes, o mesmo diminui o estresse causado pelas contrações, melhorando a dilatação, a deambulação melhora a descida fetal. O cavalinho, a bola suíça, as essências, a musicoterapia, a cromoterapia e o silêncio auxiliam na evolução do trabalho de parto e redução da dor. A acupressão e massagem auxiliam na indução e alívio da dor. Os métodos não farmacológicos são muito eficientes, aumentando sua eficácia se a mulher tiver conhecimento sobre os mesmos, para a mesma ser protagonista de seu parto o tornando mais humanizado.
\end{abstract}

Palavras-chave: Enfermagem obstétrica. Parto humanizado. Dor de parto.

\section{INTRODUÇÃO}

A assistência às mulheres durante o trabalho de parto permaneceu sendo realizada predominantemente por parteiras leigas até o século XX. Essas detinham um saber empírico e assistiam em domicílio as mulheres durante a gestação, o parto e o puerpério. Após o século XIX, foram introduzidos os médicos obstetras e a institucionalização do parto. (BRENES, 1991).

No entanto, a hospitalização do parto e como consequência a criação das maternidades, contribuíram na redução das taxas de mortalidade materno e neonatal. O Brasil vem reduzindo a taxa de mortalidade infantil reduziu $61,7 \%$ entre 1990 e 2010, mas ainda amarga o 90 lugar entre 187 países no ranking das

1 Bacharel em Enfermagem, pós-graduanda em Enfermagem Obstétrica. Enfermeira no hospital Rede de Saúde Divina Providência - Hospital Estrela. noijt@universo.univates.br

2 Bacharel em Enfermagem, especialista em Enfermagem Obstétrica, Mestre em Enfermagem. Enfermeira Obstetra no Hospital Nossa Senhora da Conceição. enfschuster@gmail.com 
Organizações das Nações Unidas (ONU). Atualmente o indicador é de 19,88 mortes por mil nascimentos vivos (BRASIL, 2012).

Acrescenta-se que a taxa de mortalidade materna apresentou melhora, mas está aquém do projetado, sendo que o Brasil não atingiu o quinto objetivo do milénio, com o propósito de reduzir 3/4 à razão da mortalidade materna entre 1990 a 2015. Permanece no foco da saúde global, principalmente a do Brasil, a redução destes índices, aos quais poderiam ser melhorados, utilizando ações dos serviços de saúde a partir de atenção adequada ao pré-natal, ao parto, e ao abortamento (BRASIL, 2017).

As últimas décadas foram marcadas por uma mudança na forma de nascer: a cirurgia cesariana transformou-se na maneira mais comum de nascimento no país. A taxa do referido procedimento situa-se em torno de $56 \%$ - com variação entre os serviços públicos e privados. O Ministério da Saúde ressalta que as cesarianas podem acrescentar riscos desnecessários quando realizadas sem indicação justificável (OLIVEIRA et al., 2016).

De acordo com os dados do Sistema de Informação sobre Nascidos Vivos (SISNASC), o Brasil garantiu a liderança no ranking mundial de cesarianas. No estado do Rio Grande do Sul, a situação demonstra-se ainda mais grave, já que a taxa é de $63 \%$ a redução e o controle deste indicador apresentam-se como grandes desafios. Nesse contexto, estudos recentes da OMS sugerem que taxas de cesariana superiores a $15 \%$ não auxiliam na redução da mortalidade materna, perinatal ou neonatal (OMS, 2015).

Com o propósito de qualificar a assistência obstétrica e reduzir as taxas de cesariana e intervenções desnecessárias o MS vem emitindo uma série de documentos e portarias visando induzir a reorganização das práticas assistenciais, cujo objetivo é à qualificação assistencial materna e neonatal. No ano de 2011 foi lançada a Portaria $n^{\circ}$ 1.459, que institui, no âmbito do SUS, a Rede Cegonha (RC), que tem como meta a elaboração de um novo modelo de atenção ao parto e nascimento e à saúde da criança (BRASIL, 2011).

A inserção das enfermeiras obstétricas, na construção dessa nova proposta de modelo é fundamental para resgatar o processo fisiológico do parto vaginal, deixando a mulher ser a protagonista do evento e ainda, favorecendo um ambiente acolhedor, oportunizando a presença do acompanhante, promovendo suporte físico, emocional e reduzindo as intervenções (VELHO; OLIVEIRA; SANTOS, 2010; VOGT; SILVA; DIAS, 2014).

O uso das tecnologias não invasivas de cuidado favorece a assistência contínua, proporciona apoio emocional, conforto físico e comunicação efetiva entre a equipe de saúde, parturiente e o acompanhante e, ainda, promove uma diminuição da sensação dolorosa relacionada ao processo parturitivo. Tendo métodos que podem ser utilizados de forma isolada ou combinados, como a acupuntura, hidroterapia, terapias térmicas, bola suíça e exercícios perineais, 
musicoterapia, acupressão, técnica de respiração e reflexologia por meio de massagem (MASCARENHAS et al., 2019).

O interesse para a realização deste estudo surgiu pela necessidade de compreender sobre as técnicas disponíveis e que possuem comprovação científica para o cuidado com o processo parturitivo. A escolha do tema sobre tecnologias não invasivas de cuidado no parto como objeto de pesquisa justificase por sua importância na qualificação da assistência ao parto e nascimento, uma vez que se pergunta: quais são as tecnologias obstétricas não invasivas para a promoção do parto humanizado?

Assim, o estudo objetivou identificar o uso das tecnologias obstétricas não invasivas para a promoção do parto humanizado

\section{MÉTODO}

Nesse estudo foi adotado a abordagem metodológica da Revisão Integrativa (RI), que é um método de pesquisa que proporciona a busca, a avaliação crítica e a síntese das evidências disponíveis do tema investigado, tendo como seu produto final o conhecimento acerca do assunto a implementação de intervenções efetivas e menos onerosas na assistência à saúde e bem como a identificação de lacunas que direcionam para o desenvolvimento de futuras pesquisas (MENDES; SILVEIRA; GALVÃO, 2008).

Na etapa de coleta de dados foram utilizadas as seguintes bases: LILACS, BDENF E MEDLINE, com descritores em ciências da saúde (DECS) como: enfermagem obstétrica, parto humanizado e dor de parto. $\mathrm{O}$ cruzamento dos termos ocorreu com o marcador booleano AND assegurando a especificidade nas buscas. Os critérios de inclusão foram: artigos completos publicados em português, de acesso gratuito e online, publicados no período de 2015 a 2019 . Os critérios de exclusão foram as publicações que não responderam à questão norteadora, dissertações, teses e estudos disponíveis apenas os resumos. Esta RI levou em consideração aspectos éticos, sendo mantidas as autenticidades das ideias dos autores pesquisados e referências.

\section{RESULTADOS}

Em decorrência da busca utilizando-se os critérios de inclusão e exclusão, totalizaram 17 artigos encontrados para o estudo, conforme o Quadro 1. 
Quadro 1 - Estratégia e estudos encontrados

\begin{tabular}{|l|c|c|c|c|}
\hline Estratégia & $\begin{array}{c}\text { Total de estudos } \\
\text { encontrados (n) }\end{array}$ & $\begin{array}{c}\text { Estudos após } \\
\text { aplicar critérios } \\
\text { de inclusão (n) }\end{array}$ & $\begin{array}{c}\text { Estudos } \\
\text { após leitura } \\
\text { de título e } \\
\text { resumo (n) }\end{array}$ & $\begin{array}{c}\text { Estudos após } \\
\text { leitura de texto } \\
\text { completo (n) }\end{array}$ \\
\hline $\begin{array}{l}\text { Enfermeira } \\
\text { Obstetra } \\
\text { AND Dor de } \\
\text { parto }\end{array}$ & 90 & 10 & 4 & 4 \\
\hline $\begin{array}{l}\text { Parto } \\
\text { humanizado } \\
\text { AND } \\
\text { Enfermeira } \\
\text { Obstetra }\end{array}$ & 84 & 28 & 10 & 6 \\
\hline $\begin{array}{l}\text { Dor de Parto } \\
\text { AND Parto } \\
\text { Humanizado }\end{array}$ & 144 & 42 & 7 & 7 \\
\hline Total & 318 & 80 & 21 & 17 \\
\hline
\end{tabular}

Para a análise e interpretação dos dados foi utilizado o quadro sinóptico que será apresentado de maneira sintetizada no Quadro 2, através da elaboração de uma codificação alfanumérica (A1 a A17) com o objetivo de facilitar a identificação dos estudos durante a discussão.

Quadro 2 - Distribuição das publicações incluídas na revisão integrativa de acordo com autor, ano de publicação, título do estudo, resultados, periódico e nível de evidência

\begin{tabular}{|c|l|l|l|l|l|}
\hline N. & Autor(s) & Ano & Título do Artigo & Objetivo(s) & Conclusão \\
\hline A1 & $\begin{array}{l}\text { ALMEIDA; } \\
\text { ACOSTA; } \\
\text { PINHAL }\end{array}$ & 2015 & $\begin{array}{l}\text { Conhecimento } \\
\text { das puérperas } \\
\text { com relação aos } \\
\text { métodos não } \\
\text { farmacológicos de } \\
\text { alívio da dor do } \\
\text { parto }\end{array}$ & $\begin{array}{l}\text { Avaliar o } \\
\text { conhecimento } \\
\text { das puérperas } \\
\text { de maternidade } \\
\text { filantrópica em relação } \\
\text { aos métodos de alivio } \\
\text { da dor }\end{array}$ & $\begin{array}{l}\text { O banho de chuveiro } \\
\text { foi a MNFAD mais } \\
\text { utilizada e considerada } \\
\text { efetiva e confortável. Este } \\
\text { ofoco da deficiência de } \\
\text { conhecimento sobre tais } \\
\text { métodos está no pré-natal }\end{array}$ \\
\hline A2 & $\begin{array}{l}\text { CARVALHO } \\
\text { et al. }\end{array}$ & 2015 & $\begin{array}{l}\text { Percepção de } \\
\text { puérperas quanto } \\
\text { ao procedimento } \\
\text { da episiotomia }\end{array}$ & $\begin{array}{l}\text { Identificar a percepção } \\
\text { de puérperas quanto } \\
\text { ao procedimento da } \\
\text { episiotomia }\end{array}$ & $\begin{array}{l}\text { Foram realizadas as } \\
\text { recomendações, mas } \\
\text { precisamos ofertar os } \\
\text { recursos, respeitar as } \\
\text { escolhas delas e utilizar } \\
\text { a episiotomia de forma } \\
\text { seletiva. Manter um } \\
\text { atendimento humanizado, } \\
\text { condutas individualizadas } \\
\text { com práticas de } \\
\text { valorização que garantam } \\
\text { o direito da mulher. }\end{array}$ \\
\hline
\end{tabular}




\begin{tabular}{|c|c|c|c|c|c|}
\hline N. & Autor(s) & Ano & Título do Artigo & Objetivo(s) & Conclusão \\
\hline A3 & MOTTA et al. & 2016 & $\begin{array}{l}\text { Implementação da } \\
\text { humanização da } \\
\text { assistência ao parto } \\
\text { natural. }\end{array}$ & $\begin{array}{l}\text { Analisar a } \\
\text { implementação das } \\
\text { práticas humanizadas } \\
\text { na assistência ao parto } \\
\text { natural, fundamentada } \\
\text { no documento } \\
\text { "Boas práticas de } \\
\text { atenção ao parto e ao } \\
\text { nascimento" de } 1996 .\end{array}$ & $\begin{array}{l}\text { Foram seguidas } \\
\text { as recomendações } \\
\text { preconizadas, sendo com } \\
\text { limitações de uso dos } \\
\text { métodos de alivio da } \\
\text { dor e observou-se que } \\
\text { as mesmas não foram } \\
\text { ofertadas a todas as } \\
\text { pacientes. Observou-se } \\
\text { a suma importância da } \\
\text { presença do enfermeiro } \\
\text { obstetra para orientar e } \\
\text { sensibilizar a equipe. }\end{array}$ \\
\hline A4 & SILVA et al. & 2016 & $\begin{array}{l}\text { Os saberes das } \\
\text { mulheres acerca } \\
\text { das diferentes } \\
\text { posições de parir: } \\
\text { uma contribuição } \\
\text { para o cuidar. }\end{array}$ & $\begin{array}{l}\text { Analisar o significado } \\
\text { dos saberes das } \\
\text { mulheres o qual } \\
\text { atribuem às } \\
\text { possibilidades de se } \\
\text { optar por uma posição } \\
\text { alternativa de parto. }\end{array}$ & $\begin{array}{l}\text { As posições mais } \\
\text { verticalizadas e autonomia } \\
\text { delas permitem o } \\
\text { empoderamento durante o } \\
\text { processo de gestar e parir. } \\
\text { Sugere-se uma discussão } \\
\text { mais ampla sobre } \\
\text { posições de parir com os } \\
\text { profissionais da área da } \\
\text { saúde. }\end{array}$ \\
\hline A5 & $\begin{array}{l}\text { BRILHANTE } \\
\text { et al. }\end{array}$ & 2017 & $\begin{array}{l}\text { Avaliação de } \\
\text { partos assistidos } \\
\text { na água por } \\
\text { enfermeiras } \\
\text { obstetras. }\end{array}$ & $\begin{array}{l}\text { Avaliar os } \\
\text { indicadores do parto } \\
\text { na água, assistido } \\
\text { por enfermeiras } \\
\text { obstetras e residentes } \\
\text { de enfermagem } \\
\text { obstétrica. }\end{array}$ & $\begin{array}{l}\text { Tiveram partos com } \\
\text { menos intervenções e os } \\
\text { mesmos foram realizados } \\
\text { baseados nas boas praticas } \\
\text { de atenção ao parto e } \\
\text { nascimento. }\end{array}$ \\
\hline A6 & $\begin{array}{l}\text { SCHETTINI; } \\
\text { GRIBOSKI; } \\
\text { FAUSTINO }\end{array}$ & 2017 & $\begin{array}{l}\text { Partos normais } \\
\text { assistidos por } \\
\text { enfermeiras } \\
\text { obstétricas: posição } \\
\text { materna e a relação } \\
\text { com lacerações } \\
\text { perineais } \\
\text { espontâneas. }\end{array}$ & $\begin{array}{l}\text { Verificar a } \\
\text { relação entre o } \\
\text { posicionamento } \\
\text { no parto vaginal } \\
\text { e a ocorrência de } \\
\text { lacerações perineais } \\
\text { espontâneas em } \\
\text { mulheres assistidas } \\
\text { em uma casa de parto. }\end{array}$ & $\begin{array}{l}\text { A adoção de posturas } \\
\text { verticalizadas e } \\
\text { lateralizadas pode ter } \\
\text { influenciado no menor } \\
\text { número de complicações e } \\
\text { na satisfação das mulheres } \\
\text { por terem uma experiência } \\
\text { positiva de parto. }\end{array}$ \\
\hline A7 & SILVA et al. & 2017 & $\begin{array}{l}\text { Práticas de } \\
\text { atenção ao parto e } \\
\text { nascimento: uma } \\
\text { revisão integrativa. }\end{array}$ & $\begin{array}{l}\text { Identificar na } \\
\text { literatura científica as } \\
\text { práticas de atenção } \\
\text { ao parto e nascimento } \\
\text { desenvolvido pelos } \\
\text { profissionais de saúde } \\
\text { no Brasil. }\end{array}$ & $\begin{array}{l}\text { Esta revisão fez refletir } \\
\text { sobre a necessidade de } \\
\text { garantir uma atenção } \\
\text { materna infantil } \\
\text { qualificada. Destacou- } \\
\text { se importância da } \\
\text { qualificação, capacitação } \\
\text { profissional, o papel } \\
\text { do enfermeiro como } \\
\text { articulador deste contexto } \\
\text { e novas pesquisas com } \\
\text { enfoque multiprofissional. }\end{array}$ \\
\hline A8 & HANUM et al. & 2017 & $\begin{array}{l}\text { Estratégias não } \\
\text { farmacológicas } \\
\text { para o alívio da } \\
\text { dor no trabalho de } \\
\text { parto: efetividade } \\
\text { sob a ótica da } \\
\text { parturiente. }\end{array}$ & $\begin{array}{l}\text { Identificar métodos } \\
\text { não farmacológicos } \\
\text { empregados para o } \\
\text { alívio da dor durante } \\
\text { o trabalho de parto e } \\
\text { sua eficácia segundo } \\
\text { a percepção de } \\
\text { puérperas. }\end{array}$ & $\begin{array}{l}\text { A informação sobre os } \\
\text { métodos de alivio da dor } \\
\text { no período gravídico } \\
\text { é deficiente, a mulher } \\
\text { precisa destas informações } \\
\text { neste período para } \\
\text { consolidação. O banho } \\
\text { morno se destacou pela } \\
\text { sua eficácia na redução } \\
\text { da dor. }\end{array}$ \\
\hline
\end{tabular}




\begin{tabular}{|c|c|c|c|c|c|}
\hline N. & Autor(s) & Ano & Título do Artigo & Objetivo(s) & Conclusão \\
\hline A9 & $\begin{array}{l}\text { FEIJÃO; } \\
\text { BOECKMANN; } \\
\text { MELO }\end{array}$ & 2017 & $\begin{array}{l}\text { O conhecimento } \\
\text { de enfermeiras } \\
\text { residentes acerca } \\
\text { das boas práticas } \\
\text { na atenção ao parto }\end{array}$ & $\begin{array}{l}\text { Conhecer as } \\
\text { percepções, vivências } \\
\text { e experiências } \\
\text { de residentes } \\
\text { de Enfermagem } \\
\text { Obstétrica acerca } \\
\text { da humanização da } \\
\text { assistência pautada } \\
\text { nas boas práticas de } \\
\text { atenção ao parto de } \\
\text { risco habitual } \\
\end{array}$ & $\begin{array}{l}\text { As evidências encontradas } \\
\text { podem contribuir para } \\
\text { reflexões que auxiliem } \\
\text { a promoção das boas } \\
\text { práticas na atenção } \\
\text { obstétrica, realizar um } \\
\text { atendimento com menor } \\
\text { grau de intervenções } \\
\text { estimulando a autonomia } \\
\text { da mulher }\end{array}$ \\
\hline A10 & $\begin{array}{l}\text { LEHUGEUR; } \\
\text { STRAPASSON; } \\
\text { FRONZA }\end{array}$ & 2017 & $\begin{array}{l}\text { Manejo não } \\
\text { farmacológico de } \\
\text { alívio da dor em } \\
\text { partos assistidos } \\
\text { por enfermeira } \\
\text { obstétrica }\end{array}$ & $\begin{array}{l}\text { Caracterizar os } \\
\text { partos assistidos por } \\
\text { enfermeira obstétrica } \\
\text { quanto aos métodos } \\
\text { não farmacológicos } \\
\text { de alívio da dor no } \\
\text { processo de parturição }\end{array}$ & $\begin{array}{l}\text { Mostrou que o enfermeiro } \\
\text { obstetra favorece a } \\
\text { implementação d } \\
\text { e boas práticas. Todas } \\
\text { as mulheres estudadas } \\
\text { utilizaram algum } \\
\text { tipo de método não } \\
\text { farmacológico e puderam } \\
\text { optar a pela posição de } \\
\text { parir, obtendo desfechos } \\
\text { favoráveis. Sugere-se mais } \\
\text { estudos com enfoque na } \\
\text { eficácia do manejo não } \\
\text { farmacológico da dor no } \\
\text { processo de parturição }\end{array}$ \\
\hline A11 & $\begin{array}{l}\text { GOMES; } \\
\text { DAVIM }\end{array}$ & 2018 & $\begin{array}{l}\text { Prática do } \\
\text { enfermeiro obstetra } \\
\text { quanto ao alívio da } \\
\text { dor de parturientes }\end{array}$ & $\begin{array}{l}\text { Identificar estratégias } \\
\text { não farmacológicas } \\
\text { no alívio da dor de } \\
\text { parturientes }\end{array}$ & $\begin{array}{l}\text { Estratégias combinadas } \\
\text { mostraram efeitos } \\
\text { positivos principalmente } \\
\text { banho morno, bola de } \\
\text { bobath, deambulação e } \\
\text { banqueta no chuveiro. } \\
\text { Sugere-se mais } \\
\text { estudos para eliminar } \\
\text { barreiras e mitos que se } \\
\text { apresentam. Salienta-se a } \\
\text { importância do enfermeiro } \\
\text { obstetra para atender } \\
\text { as necessidades das } \\
\text { parturientes durante o } \\
\text { processo de parto e ter um } \\
\text { olhar holístico } \\
\end{array}$ \\
\hline A12 & SOUSA et al. & 2018 & $\begin{array}{l}\text { Percepção de } \\
\text { puérperas sobre a } \\
\text { posição vertical no } \\
\text { parto. }\end{array}$ & $\begin{array}{l}\text { Descrever a percepção } \\
\text { de puérperas acerca } \\
\text { da posição vertical } \\
\text { adotada no trabalho } \\
\text { de parto e parto. }\end{array}$ & $\begin{array}{l}\text { Avaliação positiva das } \\
\text { puérperas em relação a } \\
\text { posição de sua escolha e } \\
\text { a verticalização do parto, } \\
\text { resultando em menores } \\
\text { intervenções profissionais, } \\
\text { descida mais rápida do } \\
\text { feto, redução do tempo } \\
\text { de trabalho de parto, } \\
\text { diminuição da dor e maior } \\
\text { conforto. }\end{array}$ \\
\hline
\end{tabular}




\begin{tabular}{|c|c|c|c|c|c|}
\hline N. & Autor(s) & Ano & Título do Artigo & Objetivo(s) & Conclusão \\
\hline A13 & $\begin{array}{l}\text { GUIMARÃES } \\
\text { et al. }\end{array}$ & 2018 & $\begin{array}{l}\text { Análise de fatores } \\
\text { associados } \\
\text { à prática da } \\
\text { episiotomia }\end{array}$ & $\begin{array}{l}\text { Identificar os fatores } \\
\text { que levam enfermeiros } \\
\text { obstetras a realizarem } \\
\text { uma episiotomia }\end{array}$ & $\begin{array}{l}\text { Fatores que levam os } \\
\text { enfermeiros obstetras a } \\
\text { realizarem a episiotomia } \\
\text { são: primiparidade, } \\
\text { à rigidez perineal, } \\
\text { macrossomia e } \\
\text { prematuridade. Com isso, } \\
\text { foi possível verificar que } \\
\text { a episiotomia não previne } \\
\text { lacerações de } 3^{\circ} \text { e } 4^{\circ} \text { grau e } \\
\text { a mesma está relacionada } \\
\text { diretamente com a dor } \\
\text { genital }\end{array}$ \\
\hline A14 & ARAÚJO et al. & 2018 & $\begin{array}{l}\text { Métodos não } \\
\text { farmacológicos no } \\
\text { parto domiciliar }\end{array}$ & $\begin{array}{l}\text { Discutir acerca } \\
\text { dos métodos não } \\
\text { farmacológicos para } \\
\text { alívio da dor no parto } \\
\text { domiciliar }\end{array}$ & $\begin{array}{l}\text { Boas práticas como banho, } \\
\text { aromoterapia, bola suíça, } \\
\text { cavalinho, banquinho, } \\
\text { massagens, deambulação } \\
\text { e em seu local de moradia } \\
\text { permitem a mulher } \\
\text { manter seu protagonismo } \\
\text { e vivenciar o trabalho } \\
\text { de parto de forma mais } \\
\text { humanizada }\end{array}$ \\
\hline A15 & SOUZA et al. & 2019 & $\begin{array}{l}\text { Tecnologias } \\
\text { apropriadas } \\
\text { ao processo do } \\
\text { trabalho de parto } \\
\text { humanizado }\end{array}$ & $\begin{array}{l}\text { Refletir sobre } \\
\text { as tecnologias } \\
\text { apropriadas utilizadas } \\
\text { pelos enfermeiros } \\
\text { generalistas e } \\
\text { obstetras no processo } \\
\text { do trabalho de parto } \\
\text { humanizado }\end{array}$ & $\begin{array}{l}\text { A aplicabilidade das } \\
\text { tecnologias leve e leve- } \\
\text { dura é favorável ao parto } \\
\text { humanizado, reduzindo } \\
\text { assim os riscos de infecção } \\
\text { e mortalidade materna } \\
\text { e neonatal decorrentes } \\
\text { de intervenções } \\
\text { desnecessárias e um } \\
\text { enfermeiro obstetra } \\
\text { capacitado para resgatar o } \\
\text { parto fisiológico }\end{array}$ \\
\hline A16 & QUEIROZ et al. & 2019 & $\begin{array}{l}\text { Assistência } \\
\text { prestada às } \\
\text { mulheres que } \\
\text { foram submetidas } \\
\text { à cesariana } \\
\text { por parada de } \\
\text { progressão }\end{array}$ & $\begin{array}{l}\text { Conhecer a percepção } \\
\text { das mulheres } \\
\text { submetidas à } \\
\text { cesariana por parada } \\
\text { de progressão do } \\
\text { trabalho de parto } \\
\text { sobre a assistência } \\
\text { prestada em um } \\
\text { hospital universitário } \\
\text { do sul do Brasil }\end{array}$ & $\begin{array}{l}\text { Pelo relato das mulheres, } \\
\text { a enfermeira obstetra } \\
\text { se destacou entre os } \\
\text { profissionais da equipe, } \\
\text { no cuidado no trabalho } \\
\text { de parto, porém esse } \\
\text { cuidado não se manteve } \\
\text { de forma contínua. } \\
\text { Sugere-se a qualificação } \\
\text { dos profissionais para a } \\
\text { assistência humanizada e } \\
\text { integral às necessidades } \\
\text { das parturientes }\end{array}$ \\
\hline
\end{tabular}




\begin{tabular}{|c|l|l|l|l|l|}
\hline N. & Autor(s) & Ano & Título do Artigo & Objetivo(s) & Conclusão \\
\hline A17 & SANTOS et al. & 2019 & $\begin{array}{l}\text { Os significados e } \\
\text { sentidos do plano } \\
\text { de parto para as } \\
\text { mulheres que } \\
\text { participaram da } \\
\text { Exposição Sentidos } \\
\text { do Nascer }\end{array}$ & $\begin{array}{l}\text { Analisar a percepção } \\
\text { das mulheres que } \\
\text { realizaram o plano } \\
\text { de parto sobre a } \\
\text { experiência de parto, } \\
\text { os significados do } \\
\text { plano de parto, seus } \\
\text { elementos e a relação } \\
\text { do plano de parto com } \\
\text { o trabalho de parto e } \\
\text { parto }\end{array}$ & $\begin{array}{l}\text { A construção do plano } \\
\text { pelas mulheres durante } \\
\text { o pré-natal e a realização } \\
\text { dele por parte da equipe } \\
\text { de saúde contribuíram } \\
\text { para o desenvolvimento } \\
\text { e desfecho favorável } \\
\text { e mais prazeroso do } \\
\text { trabalho de parto. É } \\
\text { um potencializador de } \\
\text { autonomia das mulheres } \\
\text { e família e incentivo ao } \\
\text { cuidado compartilhado }\end{array}$ \\
\hline
\end{tabular}

Fonte: do autor, 2020.

Os estudos foram elencados em quatro categorias temáticas conforme Quadro 3.

Quadro 3 - Publicações agrupadas por categorias

\begin{tabular}{|c|c|c|c|}
\hline & Ano & Título do Artigo & Categoria \\
\hline A5 & 2017 & $\begin{array}{l}\text { Avaliação de partos assistidos na água por enfermeiras } \\
\text { obstetras }\end{array}$ & \multirow{6}{*}{$\begin{array}{c}\text { Categoria } 1 \\
\text { O cuidado } \\
\text { assistencial } \\
\text { da mulher } \\
\text { no processo } \\
\text { parturitivo }\end{array}$} \\
\hline A8 & 2017 & $\begin{array}{l}\text { Estratégias não farmacológicas para o alívio da dor no } \\
\text { trabalho de parto: efetividade sob a ótica da parturiente }\end{array}$ & \\
\hline A10 & 2017 & $\begin{array}{l}\text { Manejo não farmacológico de alívio da dor em partos } \\
\text { assistidos por enfermeira obstétrica }\end{array}$ & \\
\hline A11 & 2018 & $\begin{array}{l}\text { Prática do enfermeiro obstetra quanto ao alívio da dor de } \\
\text { parturientes }\end{array}$ & \\
\hline A14 & 2018 & Métodos não farmacológicos no parto domiciliar & \\
\hline A15 & 2019 & $\begin{array}{l}\text { Tecnologias apropriadas ao processo do trabalho de parto } \\
\text { humanizado }\end{array}$ & \\
\hline A1 & 2015 & $\begin{array}{l}\text { Conhecimento das puérperas com relação aos métodos não } \\
\text { farmacológicos de alívio da dor do parto }\end{array}$ & \multirow{5}{*}{$\begin{array}{c}\text { Categoria } 2 \\
\text { O Conhecimento } \\
\text { como forma de } \\
\text { transformação } \\
\text { do parto e } \\
\text { nascimento }\end{array}$} \\
\hline A3 & 2016 & $\begin{array}{c}\text { Implementação da humanização da assistência ao parto } \\
\text { natural }\end{array}$ & \\
\hline A9 & 2017 & $\begin{array}{l}\text { O conhecimento de enfermeiras residentes acerca das boas } \\
\text { práticas na atenção ao parto }\end{array}$ & \\
\hline A7 & 2017 & $\begin{array}{c}\text { Práticas de atenção ao parto e nascimento: uma revisão } \\
\text { integrativa }\end{array}$ & \\
\hline A17 & 2019 & $\begin{array}{l}\text { Os significados e sentidos do plano de parto para as } \\
\text { mulheres que participaram da exposição Sentidos do } \\
\text { Nascer }\end{array}$ & \\
\hline A4 & 2016 & $\begin{array}{l}\text { Os saberes das mulheres acerca das diferentes posições de } \\
\text { parir: uma contribuição para o cuidar }\end{array}$ & \multirow{3}{*}{$\begin{array}{c}\text { Categoria } 3 \\
\text { Posições maternas } \\
\text { para o período } \\
\text { expulsivo no } \\
\text { parto humanizado }\end{array}$} \\
\hline A6 & 2017 & $\begin{array}{l}\text { Partos normais assistidos por enfermeiras obstétricas: } \\
\text { posição materna e a relação com lacerações perineais } \\
\text { espontâneas }\end{array}$ & \\
\hline A12 & 2018 & Percepção de puérperas sobre a posição vertical no parto & \\
\hline
\end{tabular}




\begin{tabular}{|c|c|c|c|}
\hline & Ano & Título do Artigo & Categoria \\
\hline A2 & 2015 & $\begin{array}{c}\text { Percepção de puérperas quanto ao procedimento da } \\
\text { episiotomia }\end{array}$ & $\begin{array}{c}\text { Categoria } 4 \\
\text { As intervenções } \\
\text { assistenciais } \\
\text { que devem ser } \\
\text { evitadas durante } \\
\text { o processo } \\
\text { parturitivo }\end{array}$ \\
\hline A16 & 2018 & Análise de fatores associados à prática da episiotomia \\
\hline
\end{tabular}

Fonte: do autor, 2020.

Em 36,29\% dos estudos (6 artigos) falam sobre o cuidado da mulher no processo de parto humanizado, $29,41 \%$ ( 5 artigos) falam sobre o conhecimento como forma de transformação do parto e nascimento, 17,64\% (3 artigos) sobre as melhores posições para o período expulsivo e 17,64\% ( 3 artigos) descrevem as intervenções assistenciais que devem ser evitadas durante o processo parturitivo.

\section{DISCUSSÃO}

Após a interpretação dos dados e o agrupamento dos estudos por categorias conforme a Figura 3 foi realizada a discussão de acordo com cada categoria.

\subsection{O cuidado assistencial da mulher no processo parturitivo}

A dor faz parte da natureza humana, mas ela não é algo fácil de ser vivida e entendida. É preciso paciência e autoconhecimento, principalmente quando se trata da dor de parto pois ela não está associada a alguma patologia, mas faz parte do processo do nascimento de um novo ser. Infelizmente, por falta de conhecimento sobre esse processo, as mulheres acabam relacionando a dor com o sofrimento, o que ocasiona uma insatisfação relacionada ao parto. Para melhorar este cenário foram estudados métodos de alívio da dor para serem aplicadas durante o decorrer do processo de parir, respeitando sempre cada estágio do nascimento (ARAÚJO et al., 2018; GOMES; DAVIM, 2018).

Acrescenta-se que, em média $76 \%$ das mulheres não recebem adequadamente as informações sobre os métodos de alívio da dor e de como serão utilizados, mas em contrapartida mostrou que o nível de satisfação é de $95,2 \%$ com o uso dos métodos de alívio pelas mulheres que puderam usufruir dessa tecnologia de cuidado. Esses dados indicam uma deficiência de conhecimento sobre os métodos não farmacológicos e a sua importância no processo parturitivo (HANUM et al., 2017).

$\mathrm{Na}$ assistência obstétrica temos disponíveis diversas tecnologias não invasivas do cuidado de alívio da dor entre elas podem dar destaque para o banho relaxante que é o mais aceito pelas mulheres, por proporcionar uma 
redução da ansiedade e alívio da dor de parto pois promove o relaxamento. $\mathrm{O}$ calor da água estimula os termorreceptores da epiderme, alcançando o sistema nervoso central e bloqueando a percepção da dor e, ainda, faz aumentar a circulação sanguínea, diminuindo o estresse provocado pelas contrações. Com o relaxamento do corpo da mulher, acontece a liberação de endorfinas pela hipófise e isso ocasiona uma dilatação mais efetiva do colo uterino, que proporciona uma descida mais rápida e adequada do bebê (ARAÚJO et al., 2018; BRILHANTE et al., 2017; GOMES; DAVIM, 2018; HANUM et al., 2017; SOUZA et al., 2019).

Outro método aliado seria a deambulação que tem como característica acelerar o trabalho de parto, pois ocorre uma maior mobilidade pélvica, que auxilia na aceleração da dilatação cervical, a descida fetal e reduz o tempo de trabalho de parto, auxiliado eficazmente pela posição verticalizada e pelo efeito da gravidade e também deve ser incentivada a variedade de posições entre sentada, decúbito lateral, ajoelhada, agachada, quatro apoios e em pé, dentre outras, para uma adequada evolução do trabalho de parto (ARAUJO et al., 2018; GOMES; DAVIM, 2018; LEHUGEUR; STRAPASSON; FRONZA, 2017).

Acrescenta-se também outras duas tecnologias que são o cavalinho banquinho em formato de "U" semelhante a uma cadeira de assento invertido (UFRJ, 2020) e a bola suíça desenvolvida por Aquino Cosani em (RANGEL, 2018). Essas são belas ferramentas aliadas no processo de evolução do trabalho de parto, pois permitem uma maior liberdade de variação de posições, assim favorecendo o mecanismo da musculatura do assoalho pélvico (ARAÚJO et al., 2018; GOMES; DAVIM, 2018; HANUM et al., 2017; LEHUGEUR; STRAPASSON; FRONZA, 2017; SOUZA et al., 2019).

A aromaterapia é um tratamento complementar não medicalizado, que utiliza os sentidos do toque e cheiro e explora o poder das plantas, através de óleos essenciais específicos, para o alívio da dor, redução da ansiedade e evolução do trabalho de parto. As essências utilizadas podem ser absorvidas por meio de inalação e/ou por uso tópico na pele. Ao ser inalado impulsiona os receptores sensitivos através do cérebro envolvendo partes neurológicas específicas e substâncias que se harmonizam, resultam em mudança física e psicológica e na pele a penetração ocorre através de ductos das glândulas sebáceas, folículos pilosos e através das células da pele, as mesmas os levam aos receptores sensitivos (ARAÚJO et al., 2018; HANUM et al., 2017; LEHUGEUR; STRAPASSON; FRONZA, 2017; SOUZA et al., 2019).

Em adição, temos a utilização da musicoterapia que é uma técnica capaz de reduzir o estresse, a ansiedade, a aflição e ainda, amplia o vigor e o ânimo resultando no alívio da dor. O som emitido através da música é capaz de circundar diversas áreas do encéfalo - regiões vinculadas a parte emocional e ao circuito de recompensas - que são acionadas quando a influência de algum convite associado a sobrevivência como alimentação e sexualidade. Aliada a musicoterapia, temos a cromoterapia que é uma ciência que utiliza as cores 
do espectro solar para manter ou mudar as vibrações do corpo humano numa frequência que resulte em saúde (APANAT, 2019). O uso das técnicas acima proporcionam a parturiente um estado de bem estar e saúde favorecendo $O$ trabalho de parto deixando o ambiente mais acolhedor e confortável (ARAÚJO et al., 2018; GOMES; DAVIM, 2018).

Outra tecnologia de cuidado não invasivo utilizado na assistência ao trabalho de parto é o rebozo que utiliza um xale, na posição vertical ou de cócoras, amarrado no alto, ou através de alongamentos de pelve realizados durante as contrações, correlacionados à fricção na lombar com esse tecido. Ainda, a acupressão é a utilização das pontas dos dedos para fazer pressão sobre certos pontos específicos do corpo para auxiliar na indução do parto e redução da dor. Na massagem, temos o relaxamento e aumento do fluxo sanguíneo, dando mais eficácia se a mesma for realizada pelo acompanhante, o qual faz com que a parturiente sinta a sensação de alívio, com isso conseguese promover a estimulação sensorial do toque sistêmico e manipulação dos tecidos (ARAÚJO et al., 2018; GOMES; DAVIM, 2018; HANUM et al., 2017; LEHUGEUR; STRAPASSON; FRONZA, 2017).

Outro cuidado importante com a mulher no processo de parto humanizado é a assistência baseada em evidência científica dentro do componente parto e nascimento, prática recomendada pelo MS. Uma das indicações é a inclusão dos enfermeiros obstetras na assistência aos partos classificados de risco habitual, pois a inclusão dessa classe profissional irá promover o modelo centrado na fisiologia do parto, tendo a mulher como a grande protagonista e, ainda, irá permitir a implementação de tecnologias não invasivas do cuidado de alívio da dor e todas as outras boas práticas de assistência ao parto e nascimento (BRILHANTE et al., 2017; LEHUGEUR; STRAPASSON; FRONZA, 2017; SOUZA et al., 2019).

Em suma, as supracitadas técnicas podem proporcionar um relaxamento muscular progressivo, em que o objetivo é de suprir o estado de tensão muscular e melhorar a oxigenação uterina, o qual contribui para economizar energia para o controle psíquico e sendo útil entre as contrações uterinas. A prática obstétrica, livre de intervenções desnecessárias, é realizada em um ambiente equilibrado, confortável, acolhedor, com estratégias de alívio da dor e o fortalecimento dos partos hands off. Todo esse cenário também aumenta satisfação quanto à parturição, salientando a importância da parturiente no processo de parto, a qual ficará mais empoderada para fazer suas escolhas durante este importante momento (GOMES; DAVIM, 2018; HANUM et al., 2017).

Enfim podemos observar que são vários estudos que comprovam a eficácia dos métodos não farmacológicos para o alívio da dor, o que resulta em um parto mais consciente, tranquilo e humanizado. Temos um grande desafio para disseminar esses conhecimentos para as mulheres durante todo o período gestacional, para que essa informação seja solidificada e se torne realidade durante o processo parturitivo. 


\subsection{O conhecimento como forma de transformação do parto e nascimento}

A informação disseminada precocemente é algo valioso para obter resultados satisfatórios na assistência obstétrica. Em estudos realizados com gestantes percebe-se que a maioria delas não teve acesso a informações sobre os métodos de alívio da dor para o parto durante o período pré-natal. Os dados mostram que 79,4\% das gestantes não obtiveram informações durante $o$ período gestacional na assistência prestada pelas unidades básicas de saúde. As informações foram passadas durante o período de trabalho de parto e somente $8,6 \%$ não obtiveram nenhuma informação, por não ter tempo hábil de absorver a informação e colocá-la em prática. As informações fornecidas na maternidade não são consolidadas e absorvidas pelas parturientes, dados mostram que $61,5 \%$ das mulheres referem que a informação fornecida ajudou muito, $14,4 \%$ mostraram-se indiferentes, $11,5 \%$ relatou que não ajudou, $10,6 \%$ que ajudou pouco e $1,9 \%$ das mulheres referiram que não deu tempo de avaliar. Diante disso, podemos concluir que se a informação fosse fornecida previamente durante o pré-natal, a mulher provavelmente ficaria mais tranquila para vivenciar o período parturitivo e, além disso, os resultados de satisfação durante o parto seriam melhores (ALMEIDA; ACOSTA; PINHAL, 2015).

Acrescenta-se, que é necessário ter profissionais de saúde capacitados e sensibilizados na assistência obstétrica para que ocorra a garantia de oferta de uma assistência respeitosa e baseada em evidência científica proporcionando os princípios do parto humanizado. Esse fato implicará na qualificação assistencial e, consequentemente, a redução da morbimortalidade materna e neonatal. Portanto, esse modelo assistencial evitará o uso de práticas prejudiciais como a cateterização venosa profilática, posição supina no período expulsivo, pressão no fundo do útero durante o trabalho de parto - manobra de kristeller -, o uso rotineiro de ocitocina exógena, restrição hídrica e alimentar durante o trabalho de parto, transferência rotineira para outra sala no segundo estágio do trabalho de parto e uso da episiotomia (FEIJÃO; BOECKMANN; MELO, 2017; MOTTA et al., 2016; SILVA et al., 2017).

Além disso, é necessário ter um consenso de linguagem e conduta entre as diferentes classes profissionais que assistem ao parto (médico obstetra e enfermeiro obstetra), pois por vezes, condutas embasadas cientificamente para valorização do processo fisiológico do parto e nascimento não são respeitadas por uma das partes e isso ocasiona a formação de uma barreira para a construção do vínculo entre equipe e parturiente. Essa afirmativa mostra a predominância do modelo biomédico na assistência obstétrica no Brasil mesmo após duas décadas de implantação do manual de Boas Práticas de Atenção ao Parto e Nascimento (FEIJÃO; BOECKMANN; MELO, 2017; SILVA et al., 2017).

Por outro lado, temos a adesão cada vez maior das mulheres para a realização do plano de parto em que se abordam elementos que trazem significados a elas, em relação aos seus direitos, anseios e sua participação ativa e do seu próprio cuidado. No plano de parto, os cuidados descritos pela 
mulher são relacionados ao respeito, o uso de métodos de alívio da dor, a presença do acompanhante escolhido por ela, entre outros e tem como objetivo promover uma experiência de parto agradável, menos dolorosa, reforçando sua autonomia e a execução do próprio parto (SANTOS et al., 2019).

Podemos concluir que a inserção do enfermeiro obstetra tem um grande papel na humanização do parto e nascimento, precisamos do conhecimento e entendimento das mulheres sobre o processo parturitivo e a eficácia do uso dos métodos não farmacológicos de alívio da dor do parto. Esse fato auxilia na melhora da qualidade dos nascimentos e a mulher torna-se protagonista.

\subsection{Posições maternas para o período expulsivo no parto humanizado}

O conhecimento sobre o processo parturitivo é algo imprescindível, conhecer seu próprio corpo e as posições de parir evita que as mulheres se baseiem somente nas informações e experiências de terceiros ou o que está na memória do imaginário popular que muitas vezes são assustadores. A posição lateralizada e verticalizada favorece a evolução do trabalho de parto e provocam menor índices de complicações, e essas posições têm proporcionado para as mulheres uma maior satisfação do parto, pois, respeitam o processo natural do corpo e a singularidade de cada parturiente (SCHETTINI; GRIBOSKI; FAUSTINO, 2017; SOUSA et al., 2018).

E, ainda, certas posições auxiliam na fisiologia do parto como a posição vertical, que proporciona contrações uterinas mais eficientes, pois direciona o fluxo da circulação sanguínea ocasionando contrações menos frequentes, porém com maior intensidade (SILVA et al., 2016; SOUSA et al., 2018).

Parto em posições não litotomicas melhoram a circulação útero fetal e dificultam as intervenções desnecessárias. De acordo com o A10, 62,5\% das mulheres pariram na posição semissentada, $14,7 \%$ na posição lateralizada, $7,3 \%$ de cócoras, $3 \%$ de quatro apoios e $12,5 \%$ na posição de litotomia. $\mathrm{O}$ uso de episiotomia foi de $1,3 \%$, sendo que $60,8 \%$ das mulheres apresentaram lacerações e somente $39,1 \%$ precisaram de sutura na laceração perineal. E sobre os dados neonatais, verificou-se que a média da idade gestacional calculada pelo capurro foi de 39 semanas, o apgar no primeiro minuto ficou entre $8 / 9 \mathrm{e}$ $9 / 10$ no quinto minuto e o peso médio da criança foi de $3,240 \mathrm{~kg}$. A pesquisa demonstrou um baixo índice de episiotomia e o desfecho neonatal adequado e isso pode estar relacionado ao fato da posição do parto.

Podemos concluir que o conhecimento da mulher sobre o seu corpo é muito importante e o conhecimento sobre o processo do nascimento favorece a capacidade de entender o seu corpo e utilizar meios para alívio da dor e, ainda, promover o nascimento de uma forma mais rápida e segura. Assim, resultando em menos intervenções obstétricas e promovendo o nascimento de crianças mais saudáveis. 


\subsection{As intervenções assistenciais que devem ser evitadas durante o processo parturitivo}

À primeira vista, em muitos locais percebe-se um atendimento fragmentado às gestantes e nesse modelo assistencial, diversos profissionais prestam o atendimento e cada um do seu jeito ocasionado falta de suporte contínuo à parturiente e a não permanência em tempo integral da pessoa de sua confiança. Esses fatores podem atrapalhar a evolução fisiológica do trabalho de parto. E ainda, o tipo de modelo assistencial pode repercutir negativamente em gestações futuras. A experiência negativa do trabalho de parto como falta de técnicas para o alívio da dor, pouco ou nenhum apoio emocional entre outros, pode ocasionar a escolha de um parto cirúrgico - cesariana - para concluir o processo de nascimento e assim, supostamente, evitar desfechos desagradáveis na gestação atual (QUEIROZ et al., 2019).

Em relação ao trauma perineal poderíamos diminuir os índices de episiotomias se realizarmos um reajuste no olhar profissional, tendo em vista que o parto normal é um processo fisiológico. Para evitar lacerações espontâneas deve-se buscar alternativas, como posições lateralizadas, puxo espontâneo, menos uso de ocitocina e massagem perineal no final da gestação. Desta forma se respeitaria mais o corpo e os direitos da mulher, prestandolhe um atendimento mais humanizado baseado em evidências (CARVALHO et al., 2015). O trauma perineal provocado - episiotomia- pode causar prejuízos muito grandes na vida das mulheres pois pode afetar a vida sexual por medo, vergonha das cicatrizes e até mesmo dor. E ainda, está associada a infecção, aumento da perda sanguínea, prolapso da vagina e incontinência urinária (CARVALHO et al., 2015; GUIMARÃES et al., 2018).

Uma adequada assistência obstétrica se faz importante para o bom andamento do trabalho de parto e o desfecho do mesmo, pois as mulheres muitas vezes agem passivamente, atribuindo ao profissional o papel ativo. Acrescenta-se, que interferências humanas desnecessárias na condução do processo parturitivo devem ser evitadas e o profissional deve estimular e acreditar no processo fisiológico do nascimento.

\section{CONCLUSÃO}

A partir dos resultados encontrados sobre a utilização de tecnologias não invasivas de cuidado no parto conclui-se que os mesmos trazem resultados mais eficazes se disseminados precocemente às mulheres desde o início da gestação, para as mesmas refletirem e estudarem sobre os métodos disponíveis com a finalidade de saberem a melhor forma e o momento para usar e usufruir de seus benefícios para aliviar a dor do parto.

Conforme os estudos, diversas são as técnicas possíveis de utilização pelas parturientes, desde o banho relaxante, como a deambulação, a técnica 
do rebozo, cavalinho e bola suíça, bem como a musicoterapia, cromoterapia e aromaterapia, além da acupressão.

Por fim, é importante a verificação de que mesmo cada parturiente tendo a sua percepção, entendimento e crenças, os métodos tendem a reduzir os níveis de estresse e ansiedade e promover satisfação. Tendo em vista que a dor é sentida e entendida por cada um de uma forma diferente, o uso de tecnologias não invasivas de controle da dor exige da mulher um maior senso de controle sobre seu corpo e suas emoções, fator delicado esse pois no trabalho de parto muitos sentimentos podem aflorar e por isso é tão importante o trabalho humanizado e em equipe, envolvendo sempre a família.

\section{REFERÊNCIAS}

ALMEIDA, J. M.; ACOSTA, L. G.; PINHAL, M. G. Conhecimento das puérperas com relação aos métodos não farmacológicos de alívio da dor do parto. REME Revista Mineira de Enfermagem, Belo Horizonte, v. 19, n. 3, p. 718-724, jul./set. 2015.

ARAÚJO, A. S. C. et al. Métodos não farmacológicos no parto domiciliar. Revista de Enfermagem UFPE On Line, Recife, v. 12, n. 4, p. 1091-1096, abr. 2018. Disponível em: <https://periodicos.ufpe.br/revistas/revistaenfermagem/article/view/230120>. Acesso em: 15 maio 2020.

ASSOCIAÇÃO PAULISTA DE NATUROLOGIA - APANAT. Cromoterapia. São Paulo, 2019. Disponível em: <http://apanat.org.br/cromoterapia/>. Acesso em: 3 jun. 2020.

BRASIL. Ministério da Saúde. Secretaria de Atenção à Saúde. Departamento de Ações Programáticas e Estratégicas. Coordenação-Geral de Saúde das Mulheres. Coordenação-Geral de Saúde da Criança e Aleitamento Materno. Apice on: aprimoramento e inovação no cuidado e ensino em obstetrícia e neonatologia. 1 ed. Brasília: Ministério da Saúde, 2017.

. Ministério da Saúde. Secretaria de Ciência, Tecnologia e Insumos Estratégicos. Departamento de Ciência e Tecnologia. Síntese de evidências para políticas de saúde: mortalidade perinatal. Brasília: Ministério da Saúde, 2012.

. Ministério da Saúde. Portaria no 1.459 , de 24 de junho de 2011. Institui, no âmbito do Sistema Único de Saúde - SUS - a Rede Cegonha. Diário Oficial da União, Brasília, DF, Seção 1, p. 109, 27 jun. 2011.

BRENES, A. C. História da parturição no Brasil, século XIX. Cadernos de Saúde Pública, Rio de Janeiro, v. 7, n. 2, p. 135-149, abr./jun. 1991.

BRILHANTE, A. F. et al. Avaliação de partos assistidos na água por enfermeiras obstetras. Revista de Enfermagem UFPE On Line, Recife, v. 11, n. 11, p. 4418-4423, nov. 2017. Disponível em: <https:// periodicos.ufpe.br/revistas/revistaenfermagem/ article/view/15017/pdf >. Acesso em: 15 mar. 2020. 
CARVALHO, P. D. et al. Percepção de puérperas quanto ao procedimento da episiotomia. Journal of the Health Science Institute, v. 33, n. 3, p. 228-234, jul./set. 2015. Disponível em: <https://www.unip.br/presencial/comunicacao/publicacoes / ics/edicoes/2015_03.aspx>. Acesso em: 13 mar. 2020.

FEIJÃO, L. B. V.; BOECKMANN, L. M. M.; MELO, M. C. Conhecimento de enfermeiras residentes acerca das boas práticas na atenção ao parto. Enfermagem em Foco, Brasília, v. 8, n. 3, p. 35-39, 2017.

GOMES, E. C. H.; DAVIM, R. M. B. Prática do enfermeiro obstetra quanto ao alívio da dor de parturientes. Revista de Enfermagem UFPE On Line, Recife, v. 12, n. 12, p. 3426-3435, dez. 2018. Disponível em: <https:/ / periodicos.ufpe.br/revistas / revistaenfermagem/article/viewFile/237709/30858>. Acesso em: 14 maio 2020.

GUIMARÃES, N. N. A. et al. Análise de fatores associados à prática da episiotomia. Revista de Enfermagem UFPE On Line, Recife. v. 12, n. 4, p. 1046-1053, abr. 2018. Disponível em: <https:/ / periodicos.ufpe.br/revistas/revistaenfermagem/article/ view/231010>. Acesso em: 14 maio 2020.

HANUM, S. P. et al. Estratégias não farmacológicas para o alívio da dor no trabalho de parto: efetividade sob a ótica da parturiente. Revista de Enfermagem UFPE On Line, Recife, v. 11, supl. 8, p. 3303-3309, ago. 2017. Disponível em: <https:/ / periodicos.ufpe.br/revistas/revistaenfermagem/article/viewFile/110197/22089>. Acesso em: 10 maio 2020.

LEHUGEUR, D.; STRAPASSON, M. R.; FRONZA, E. Manejo não farmacológico de alívio da dor em partos assistidos por enfermeira obstétrica. Revista de Enfermagem UFPE On Line, Recife, v. 11, n. 12, p. 4929-4937, dez. 2017. Disponível em: <https:/ / periodicos.ufpe.br/revistas/revistaenfermagem/article/viewFile/22487/25309>. Acesso em: 14 maio 2020.

MASCARENHAS, V. H. A. et al. Evidências científicas sobre métodos não farmacológicos para alívio a dor do parto. Acta Paulista de Enfermagem, São Paulo, v. 32, n. 3, p. 350-357, 2019.

MATERNIDADE ESCOLA. Enfermagem. Protocolos Assistenciais. Métodos não farmacológicos de alívio da dor no trabalho de parto. In: UNIVERSIDADE FEDERAL DO RIO DE JANEIRO - UFRJ. Rio de Janeiro, 2020. Disponível em: <http:/ / www. me.ufrj.br/index.php/atencao-a-saude/protocolos-assistenciais/enfermagem >. Acesso em: 3 jun. 2020.

MENDES, K. D. S.; SILVEIRA, R. C. C. P.; GALVÃO, C. M. Revisão integrativa: método de pesquisa para a incorporação de evidências na saúde e na enfermagem. Texto \& Contexto - Enfermagem, Florianópolis, v. 17, n. 4, p. 758-764, out./dez. 2008.

MOTTA, S. A. M. F. et al. Implementação da humanização da assistência ao parto natural. Revista de Enfermagem UFPE on line, Recife, v. 10, n. 2, p. 593-599, fev. 2016 Disponível em: <https:/ / periodicos.ufpe.br/revistas/revistaenfermagem/article/ view/10994>. Acesso em: 13 mar. 2020. 
OLIVEIRA, R. R. et al. Fatores associados ao parto cesárea nos sistemas público e privado de atenção à saúde. Revista da Escola de Enfermagem da USP, São Paulo, v. 50, n. 5, p. 734-741, set./out. 2016.

ORGANIZAÇÃO MUNDIAL DA SAÚDE - OMS. Declaração da OMS sobre taxas de cesáreas. In: OPAS BRASIL. Genebra, 10 abr. 2015. Disponível em: <https:/ / www. paho.org/bra/index.php?option=com_content\&view $=$ article\&id=4815:declaracao-daoms-sobre-taxas-de-cesareas\&Itemid=820>. Acesso em: 15 maio 2020.

QUEIROZ, R. R. et al. Assistência prestada às mulheres que foram submetidas à cesariana por parada de progressão. REME Revista Mineira de Enfermagem, Belo Horizonte, v. 23, jan. 2019.

RANGEL, M. C. Implantação do uso da bola suíça como método não farmacológico para o alívio da dor: um relato de experiência. 2018. Monografia (Especialização em Enfermagem Obstétrica) - Universidade Federal de Minas Gerais, Vitória, ES, 2018.

SANTOS, F. S. R. et al. Os significados e sentidos do plano de parto para as mulheres que participaram da Exposição Sentidos do Nascer. Cadernos de Saúde Pública, Rio de Janeiro, v. 35, n. 6, 2019. Disponível em: <scielo.br/scielo.php?script=sci arttext\&pid=S0102-311X2019000705011>. Acesso em: 15 abr. 2020.

SCHETTINI, N. J. C.; GRIBOSKI, R. A.; FAUSTINO, A. M. Partos normais assistidos por enfermeiras obstétricas: posição materna e a relação com lacerações perineais espontâneas. Revista de Enfermagem UFPE On Line, Recife, v. 11, supl. 2, p. 932-940, fev. 2017. Disponível em: <https:/ / periodicos.ufpe.br/revistas/revistaenfermagem/ article/view/13462>. Acesso em: 23 abr. 2020.

SILVA, L. S. et al. Os saberes das mulheres acerca das diferentes posições de parir: uma contribuição para o cuidar. Revista de Enfermagem UFPE On Line, Recife, v.10, supl. 4, p. 3531-3536, 2016. Disponível em: <https:/ / periodicos.ufpe.br/revistas / revistaenfermagem/article/view/11127>. Acesso em: 13 abr. 2020.

SILVA, T. C. et al. Práticas de atenção ao parto e nascimento: uma revisão integrativa. Revista de Enfermagem do Centro-Oeste Mineiro, v. 7, 2017.

SOUSA, J. L. et al. Percepção de puérperas sobre a posição vertical no parto. Revista Baiana de Enfermagem, Salvador, v. 32, 2018.

SOUZA, F. M. L.C. et al. Tecnologias apropriadas ao processo do trabalho de parto humanizado. Enfermagem em Foco, Brasília, v. 10, n. 2, p. 118-124, 2019.

VELHO, M. B.; OLIVEIRA, M. E.; SANTOS, E. K. A. Reflexões sobre a assistência de enfermagem prestada à parturiente. Revista Brasileira de Enfermagem, Brasília, v. 63, n. 4, p. 652-659, jul./ago. 2010.

VOGT, S. E.; SILVA, K. S.; DIAS, M. A. B. Comparison of childbirth care models in public hospitals, Brazil. Revista de Saúde Pública, São Paulo, v. 48, n. 2, p. 1-10, Apr. 2014. Disponível em: <http:/ / www.revistas.usp.br/rsp/article/view/81154>. Acesso em: 13 abr. 2020. 